
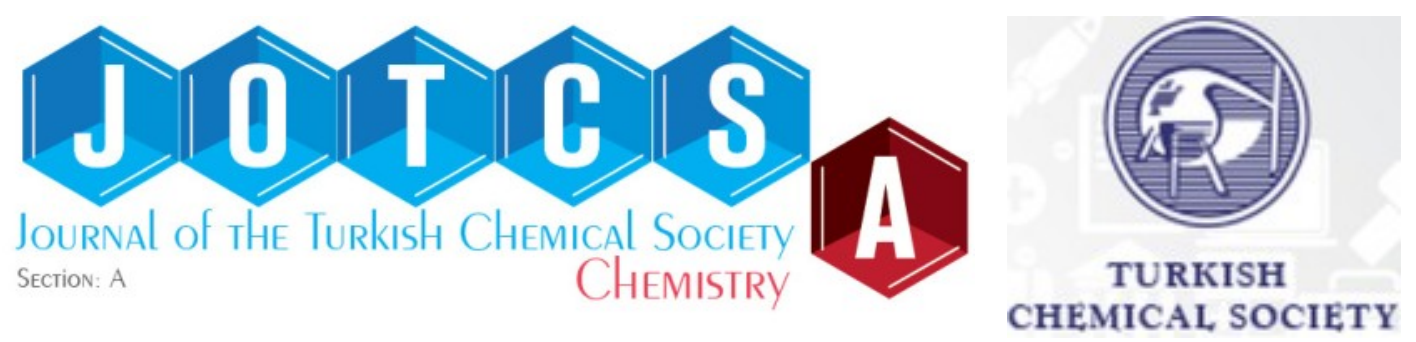

\title{
Aqueous Extracts of Aaronsohnia pubescens subsp. pubescens Aerial Parts as Green Corrosion Inhibitor for Mild Steel in Hydrochloric Acid Solution
}

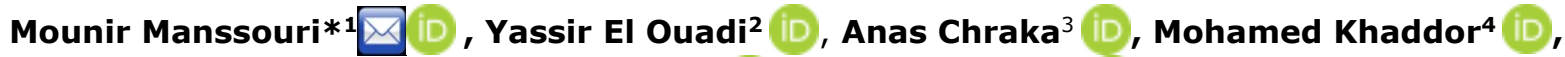 \\ Mohamed Znini ${ }^{1}$ (D) and Lhou Majidi ${ }^{1}$
}

\begin{abstract}
${ }^{1}$ Moulay Ismail University of Meknes, Laboratory of Natural Substances \&Synthesis and Molecular Dynamics, Faculty of Sciences and Techniques, BP 509, 52000, Errachidia,Morocco

2 University of Mohammed Premier, Laboratory of Analytical Chemistry, Materials, and Environment (LC2AME), Faculty of Sciences, B.P. 717, 60000 Oujda, Morocco

${ }^{3}$ Abdelmalek Essaâdi University, Materials and Interfacial Systems Laboratory, ERESI Team. Department of Chemistry, Faculty of Sciences, Avenue de Sebta, Mhannech II, 93002 Tetouan, Morocco.

${ }^{4}$ University Abdelmalek Essaadi, Laboratory of LAMSE, Faculty of Sciences and Techniques, Tangier, Morocco
\end{abstract}

\begin{abstract}
In this study, two aqueous extracts from the aerial parts of Aaronsohnia pubescens subsp. pubescens (Odorized aqueous extract (OE) and Deodorized aqueous extract (DE)) were used as some novel ecological corrosion inhibitors for mild steel (MS) in $1 \mathrm{M} \mathrm{HCl}$ medium. For this reason, the inhibition behavior of the OE and DE were investigated using weight loss measurements, electrochemical assays, kinetics, and thermodynamic parameters, and electrochemical methods, both stationary (Potentiodynamic polarization (PDP)) and transient (Electrochemical impedance spectroscopy (EIS)). The obtained results showed that EO and DE act as effective corrosion inhibitors and the inhibition efficiency of inhibitors increases for the concentration of $1.5 \mathrm{~g} / \mathrm{L}$; reaching some high values of 93.11 and $87.88 \%$ in $1 \mathrm{M} \mathrm{HCl}$ solution at $308 \mathrm{~K}$ for $\mathrm{OE}$ and $\mathrm{DE}$, respectively. Furthermore, PDP measurements exhibited that the studied of each inhibitor performs as a mixed-type inhibitor. The results of the thermodynamic kinetic parameters indicate the adsorption of OE and DE on the MS surface sites obeying the Langmuir adsorption isotherm.
\end{abstract}

Keywords: Aaronsohnia pubescens subsp. pubescens; aqueous extracts; mild Steel; ecological corrosion inhibitors; $1 \mathrm{M} \mathrm{HCl}$.

Submitted: June 13, 2021. Accepted: August 09, 2021.

Cite this: Manssouri M, El Ouadi Y, Chraka A, Khaddor M, Znini M, Majidi L. Aqueous Extracts of Aaronsohnia pubescens subsp. pubescens Aerial Parts as Green Corrosion Inhibitor for Mild Steel in Hydrochloric Acid Solution. JOTCSA. 2021;8(3):953-68.

DOI: https://doi.org/10.18596/jotcsa.951852.

*Corresponding author. E-mail: man.mounir@yahoo.fr.

\section{INTRODUCTION}

Mild Steel (MS) is extensively used in many industries such as tanks and water utilities, power production, heat exchangers, oil, chemical, and electrochemical technologies due to good mechanical strength and relatively low price, but it is susceptible to several forms of corrosion in some environments especially in the acidic environment $(1,2)$. This phenomenon can be minimized or delayed by various means such as coatings, cathodic protection, and corrosion inhibitors (3). Corrosion inhibitors, classified as inorganic and organic types, are one of the most cost-effective methods for controlling corrosion. The most wellknown acid corrosion inhibitors are organic compounds that adsorb on the MS surface and protects it from corrosion by blocking the active sites. These inhibitors are rich in electrons and can share their electrons with unoccupied d-orbitals of 
steel (4). Nowadays, the researchers' interests are directed towards environmental-friendly inhibitors (i.e., biodegradable molecules). The essential oils (EOs) and extracts components from a variety of plants origins as eco-friendly sources of sustainable corrosion inhibitors (5-9). These types of inhibitors, which are readily available through a simple extraction process, are able and effective to protect the metal from corrosion (10).

In our laboratory, a great deal of research has been carried out to study inhibitive effect several plant extract on the corrosion of steel in $1 \mathrm{M} \mathrm{HCl}$ (11-16). In this context, recently, Aaronsohnia pubescens subsp. pubescens essential oil has been established, as an eco-friendly corrosion inhibitor of acid corrosion of $\mathrm{MS}$ in $1 \mathrm{M} \mathrm{HCl}$. The inhibition efficiency IE (\%) was found to increase with naturally substance content to attain $82.11 \%$ at $1.50 \mathrm{~g} / \mathrm{L}(17)$.

The main objective of current research is to study for the first time the potency of the power of extracts from the aerial parts of Aaronsohnia pubescens subsp. pubescens Figure 1 (Odorized aqueous extract (OE) and Deodorized aqueous extract (DE)) to protect mild steel in $1 \mathrm{M} \mathrm{HCl}$ medium were assessed by WL measurement, PDP, and EIS examinations.

\section{EXPERIMENTAL PART}

\section{Inhibitors}

The experimental phase followed in the current study such as preparations of the aqueous extract
(OE and DE) have been mentioned according to a previously described experimental procedure in our work (18). A portion $(100 \mathrm{~g})$ of dried plant material was extracted with $1 \mathrm{~L}$ of water under refluxing for $3 \mathrm{~h}$. The liquid retentate was collected, filtered, and centrifuged at $5000 \mathrm{rpm}$ for $30 \mathrm{~min}$. The supernatant was also filtered to eliminate any residues and lyophilized to give finally odorized aqueous extract (OE) in a yield of $11.37 \%(\mathrm{w} / \mathrm{w})$. However, the liquid retentate obtained after completion of hydrodistillation of $100 \mathrm{~g}$ dried plant material in $1 \mathrm{~L}$ of water for $3 \mathrm{~h}$, using a Clevenger-type apparatus to isolate volatile compounds, was collected, filtered, centrifuged and lyophilized to give finally deodorized aqueous extract (DE) in a yield of $10.82 \%(w / w)(19)$.

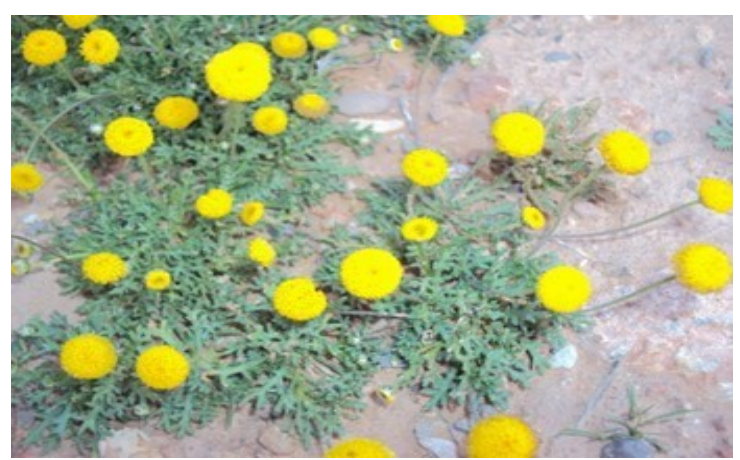

Figure 1: Aaronsohnia pubescens subsp. pubescens in its native habitat in south-eastern Morocco.

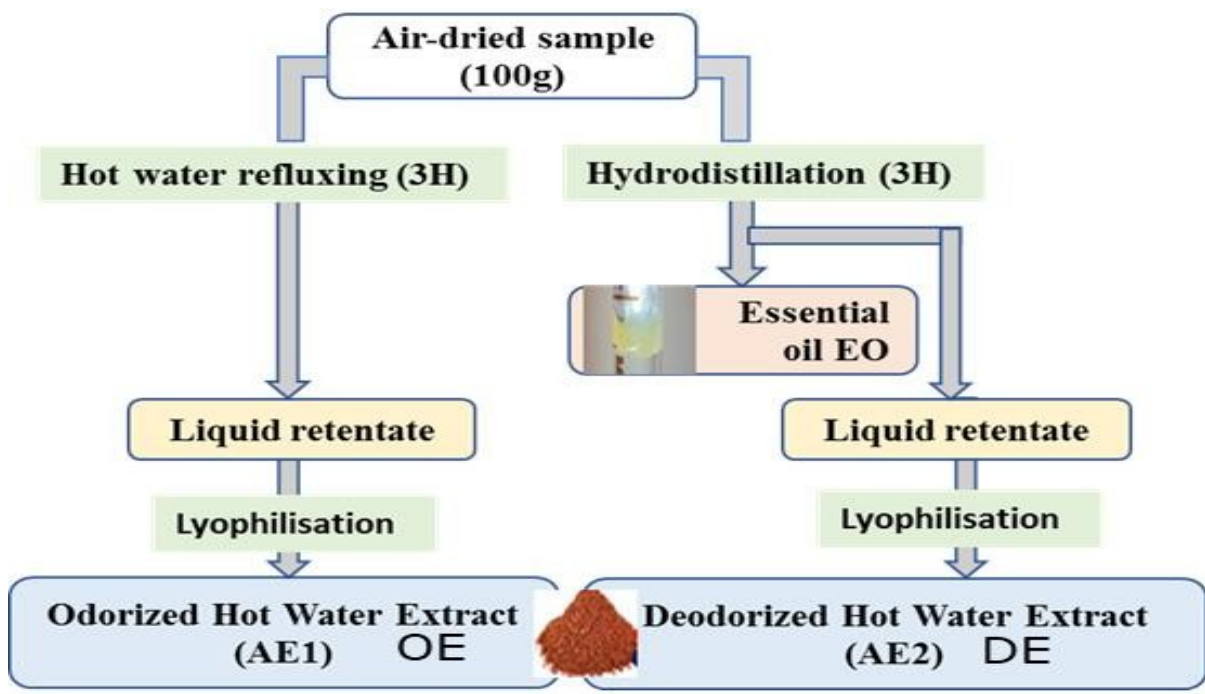

Figure 2: Scheme of the extraction methods of aqueous extracts from aerial parts of Aaronsohnia pubescens subsp. Pubescens.

\section{Corrosion test}

Corrosion inhibition on $\mathrm{MS}$ in $1 \mathrm{M} \mathrm{HCl}$ by $\mathrm{OE}$ and DE was performed by using WL, PDP and EIS methods according to the methodology described previously in our work $(13,17)$. A very low concentration range $(0.25-1.5 \mathrm{~g} / \mathrm{L})$ of inhibitors were prepared in $1 \mathrm{M} \mathrm{HCl}$ media for its corrosion inhibition potential at different temperatures (308$343 \mathrm{~K})$.

\section{Preparation of MS segments, corrosive solutions and inhibitors}

Corrosion tests were conducted on the MS segments with dimension of $2 \mathrm{~cm} \times 2 \mathrm{~cm} \times 0.05 \mathrm{~cm}$; the MS metal presents the subsequent composition 
with mass percentage (\%): $\mathrm{P} 0.09$, Si $0.38, \mathrm{Al}$ 0.01 , Mn 0.05, C 0.21, S 0.05 and Fe 99.21. Before each corrosion test, the MS segments were mechanically ground with sequential grades of emery papers (400, 600 and 1200 grit), and ensuing rinsed and degreased with distilled water and acetone, then dried and weighed. The corrosive acid solution was a molar hydrochloric acid (1 $\mathrm{M}$ of $\mathrm{HCl}$ ), was prepared from concentrated commercial acid of $\mathrm{HCl}(37 \%)$ by dilution with distilled water.

\section{Electrochemical (PDP and EIS) measurements}

Before conducting each electrochemical corrosion test, the sample was immersed in the test solution during $30 \mathrm{~min}$ at the open circuit potential (EocP) to find a steady state. Both PDP and EIS tests were performed from utilizing an assembly of electrochemical cell containing three electrodes: a disc cut from the MS as working electrode $\left(1 \mathrm{~cm}^{2}\right)$, a saturated calomel electrode as a reference electrode, and a platinum electrode as counter electrode. All electrochemical measurements were carried out using a potentiostat/galvanostat (Model PAR 263A) and the electrochemical parameter values were determined using the Volta Master 4 software. We note that all potentials measurement in this study were obtained with respect to the potential value of the reference electrode.

\section{RESULTS AND DISCUSSION}

Effect of both concentration and temperature The effect of different concentrations of $\mathrm{OE}$ and $\mathrm{DE}$ on $\mathrm{MS}$ corrosion in $1 \mathrm{M} \mathrm{HCl}$ at $308 \mathrm{~K}$ was investigated using the gravimetric method. The inhibition efficiency (IEw (\%)) was calculated on the basis of the Equation 1:

$$
\mathrm{IE} \%=\frac{\mathrm{W}_{\text {corr }}-\mathrm{W}_{\text {corr(inh) }}}{\mathrm{W}_{\text {corr }}} \times 100(\text { Eq. 1) }
$$

where Wcorr and Wcorr (inh) are the values of corrosion rate of $\mathrm{MS}$ in $1 \mathrm{M} \mathrm{HCl}$ medium without and with the addition of the aqueous extracts tested.

The obtained results of the study are summarized in Table 1 . It shows that the corrosion rate reduces and the IE (\%) increase with concentrations and reach a maximum value of 93.46 and $80.48 \%$ at $1.5 \mathrm{~g} / \mathrm{L}$ of $\mathrm{OE}$ and $\mathrm{DE}$, respectively. These results suggesting that the aqueous extracts inhibited the corrosion of MS in a dose-dependent manner. This behavior can be attributed to the strong interaction of the compounds forming these extracts with the metal surface. In other words, we observed that the inhibition efficiency of $O E$ is slightly increased when the temperature media increases, which results probably to the chemisorption behavior of OE onto MS surface.

\section{PDP investigation}

The effect of EO and DE at $308 \mathrm{~K}$ on anodic and cathodic reactions was demonstrated by PDP plots in $1 \mathrm{M} \mathrm{HCl}$ medium and the embodiments obtained are displayed in Figures 3 and 4. The outputted parameters of PDP analysis including the potential of corrosion ( $\left.E_{c o r r}\right)$, the current density of corrosion $\left(\mathrm{I}_{\text {corr }}\right.$ ) and cathodic and anodic Tafel slopes ( $\beta a$ and $\beta c$ ) are given in Table 2 . The corrosion inhibition efficiency $\mathrm{IE}_{\mathrm{PDP}}(\%)$ was derived as given below:

$$
\mathrm{IE}_{\mathrm{PDP}} \%=\left(\frac{I_{c o r r}-I_{c o r r, i n h}}{I_{c o r r}}\right) \times 100
$$

Where $I_{\text {corr }}$ and $I_{\text {corr, inh }}$ are the corrosion current densities in the absence and the presence of inhibitor, respectively.

According to Figures 3 and 4, we have noticed that the use of OE and DE at $308 \mathrm{~K}$ are suppressed both the cathodic hydrogen development and anodic metal dissolution reactions. Moreover, the PDP curves in the inhibited solutions were translated into lower current densities. The polarization diagrams noted that the addition of different concentrations of the two aqueous extracts that both the cathodic and anodic reactions did not affect, as well as the corresponding $E_{\text {corr }}$ appeared to be approximately constant significant. Therefore, EO and DE can be classified as mixed-type inhibitors (20). In addition, the results of Table 2 indicate that the rate of the $I_{\text {corrvalues of }} \mathrm{MS}$ is decreased with an increase in the concentrations of the two inhibitors; reaching some high values of 517 and $862 \mu \mathrm{A} / \mathrm{cm}^{2}$ in $1 \mathrm{M} \mathrm{HCl}$ solution at $308 \mathrm{~K}$ for $\mathrm{OE}$ and $\mathrm{DE}$, respectively at $1.5 \mathrm{~g} / \mathrm{L}$. These results suggest that the addition of $E O$ and $D E$ loading more compounds of both adsorbed on the MS surface, and thus the corrosion-resistant film can be generated on the metal surface (21). As shown in Table 2, the $\operatorname{IE}_{\mathrm{PDP}}(\%)$ of $\mathrm{EO}$ and DE in the $1 \mathrm{M}$ $\mathrm{HCl}$ solution is about $91.02 \%$ and $85.05 \%$ respectively. It can be concluded from these findings that both aqueous extracts provided the good anti-corrosion performance, with a clear preference for OE. 
Table 1: Weight loss results for $\mathrm{MS}$ in $1 \mathrm{M} \mathrm{HCl}$ with and without different concentrations of aqueous extracts (OE and $\mathrm{DE}$ ) at different temperatures.

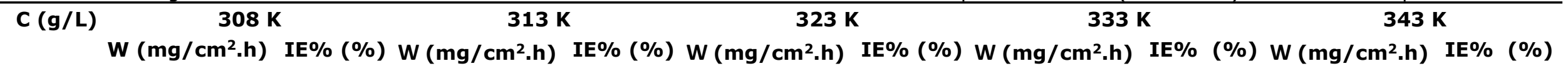

\begin{tabular}{|c|c|c|c|c|c|c|c|c|c|c|}
\hline $\begin{array}{c}\text { OE 1M HCl } \\
0.25\end{array}$ & $\begin{array}{l}\mathbf{0 . 9 4 2} \\
0.186\end{array}$ & 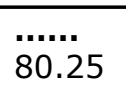 & $\begin{array}{l}\mathbf{1 . 7 5 1} \\
0.344\end{array}$ & $\begin{array}{l}\mathrm{A} . . . \\
80.37\end{array}$ & $\begin{array}{l}\mathbf{2 . 8 3 6} \\
0.532\end{array}$ & $\begin{array}{l}\mathrm{a} . . . \\
81.24\end{array}$ & $\begin{array}{l}\mathbf{3 . 6 4 1} \\
0.682\end{array}$ & $\begin{array}{l}\mathrm{A} \cdot . .28 \\
81.28\end{array}$ & $\begin{array}{l}\mathbf{6 . 3 0 1} \\
1.115\end{array}$ & $\begin{array}{l}\ldots . . \\
82.30\end{array}$ \\
\hline 0.50 & 0.116 & 87.66 & 0.214 & 87.78 & 0.320 & 88.70 & 0.409 & 88.78 & 0.638 & 89.88 \\
\hline 1.00 & 0.108 & 88.58 & 0.197 & 88.74 & 0.315 & 88.88 & 0.404 & 88.90 & 0.633 & 89.96 \\
\hline 1.50 & 0.065 & 93.11 & 0.119 & 93.22 & 0.189 & 93.33 & 0.241 & 93.39 & 0.412 & 93.46 \\
\hline DE 0.25 & 0.224 & 76.21 & 0.470 & 73.15 & 0.824 & 70.95 & 1.064 & 70.77 & 1.872 & 70.29 \\
\hline 0.50 & 0.193 & 79.50 & 0.378 & 78.44 & 0.622 & 78.08 & 0.822 & 77.42 & 1.426 & 77.37 \\
\hline 1.00 & 0.152 & 83.89 & 0.309 & 82.38 & 0.507 & 82.12 & 0.667 & 81.68 & 1.170 & 81.43 \\
\hline 1.50 & 0.114 & 87.88 & 0.276 & 84.23 & 0.473 & 83.33 & 0.621 & 82.95 & 1.230 & 80.48 \\
\hline
\end{tabular}




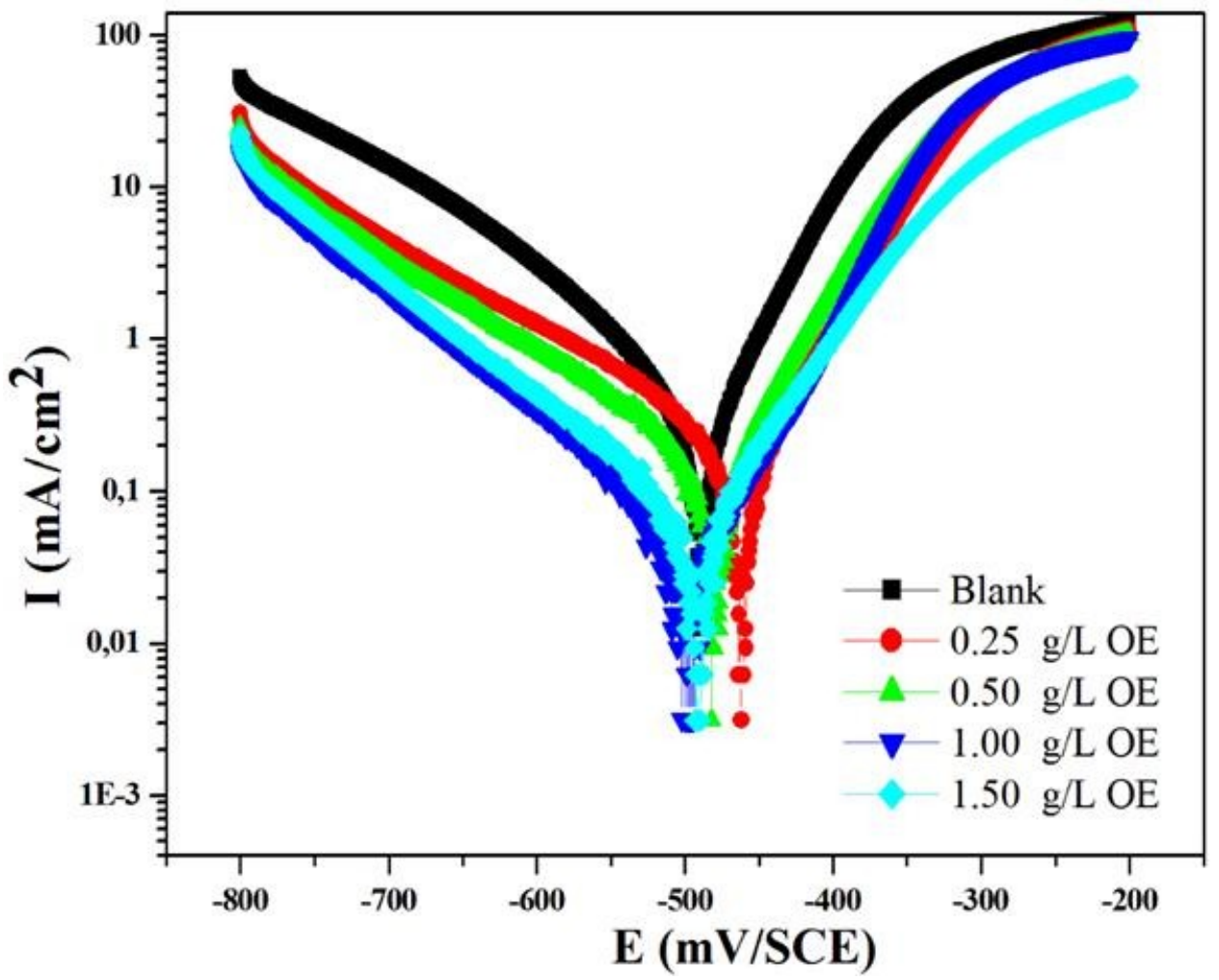

Figure 3: Anodic and cathodic polarization curves of $\mathrm{MS}$ in solutions of $1 \mathrm{M} \mathrm{HCl}$ without and with different concentrations of odorized extract.

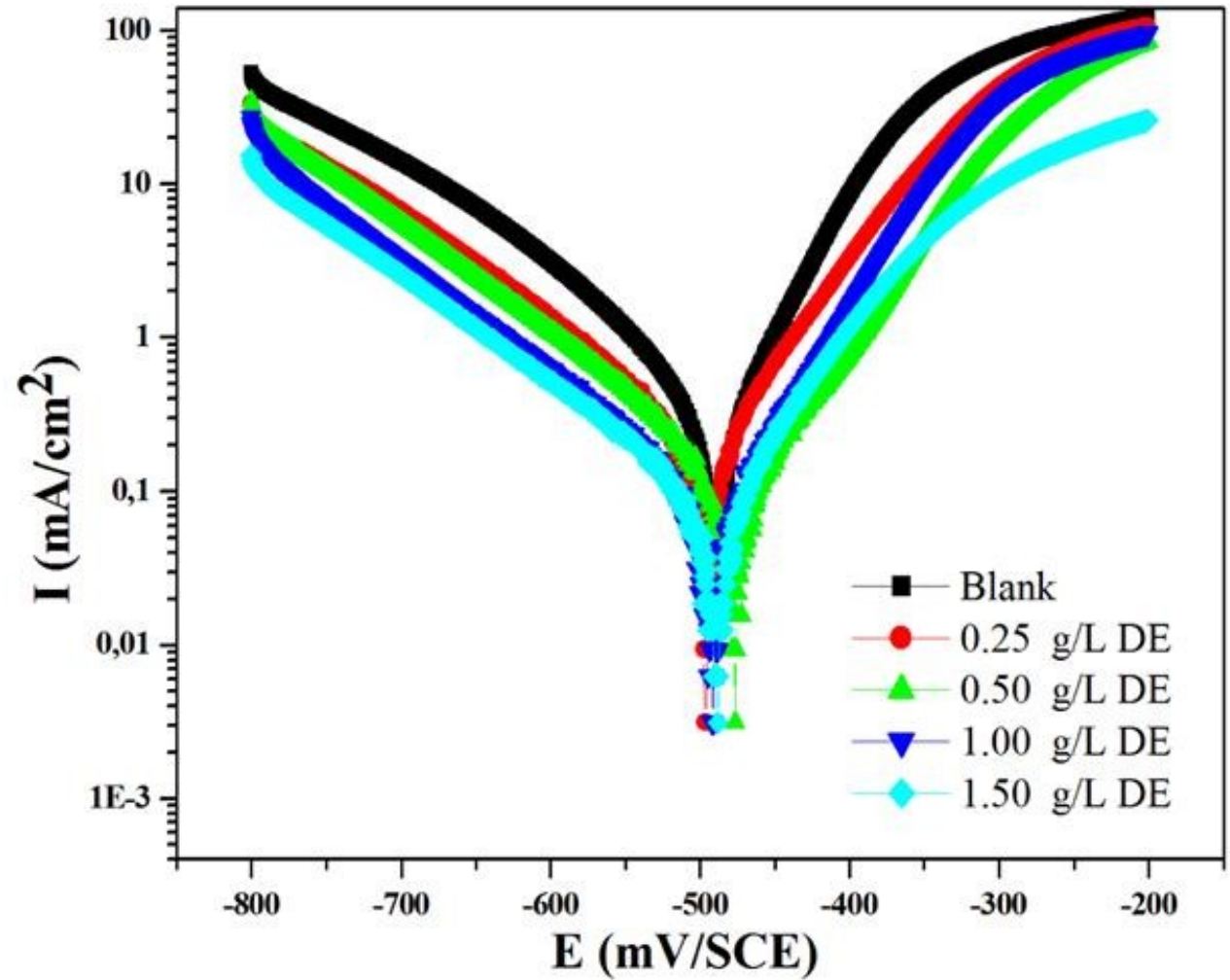

Figure 4: Anodic and cathodic polarization curves of $\mathrm{MS}$ in solutions of $1 \mathrm{M} \mathrm{HCl}$ without and with different concentrations of deodorized extract. 
Table 2: Electrochemical parameters for the $\mathrm{MS}$ in $1 \mathrm{M} \mathrm{HCl}$ with and without various concentrations of aqueous extracts from Aaronsohnia pubescens aerial parts (OE and DE) at $308 \mathrm{~K}$.

\begin{tabular}{|c|c|c|c|c|c|c|}
\hline & $\begin{array}{c}C \\
(g / L)\end{array}$ & $\begin{array}{c}-E_{\text {corr }} \\
(\mathrm{mV} / \mathrm{SCE})\end{array}$ & $\begin{array}{c}I_{\text {corr }} \\
\left(\mathrm{mA} \mathrm{cm}^{-2}\right)\end{array}$ & $\begin{array}{c}-\beta c \\
\left.\left(m V^{-1 e c}\right)^{-1}\right)\end{array}$ & $\begin{array}{c}\beta a \\
\left(m V^{d e c}{ }^{-1}\right)\end{array}$ & IEPDP (\%) \\
\hline $1 \mathrm{M} \mathrm{HCl}$ & & 490.0 & 0.5779 & 147.4 & 74.8 & $\ldots \ldots \ldots \ldots \ldots$ \\
\hline \multirow{4}{*}{ OE } & 0.25 & 462.9 & 0.1145 & 110.2 & 60.8 & 80.18 \\
\hline & 0.50 & 460.1 & 0.0857 & 100.1 & 67.1 & 85.17 \\
\hline & 1.00 & 498.9 & 0.0701 & 109.2 & 62.9 & 87.86 \\
\hline & 1.50 & 497.0 & 0.0517 & 100.7 & 65.0 & 91.02 \\
\hline \multirow{4}{*}{ DE } & 0.25 & 497.8 & 0.1651 & 110.6 & 74.3 & 71.43 \\
\hline & 0.50 & 480.8 & 0.0997 & 104.8 & 73.5 & 82.74 \\
\hline & 1.00 & 495.3 & 0.0897 & 110.7 & 72.1 & 84.47 \\
\hline & 1.50 & 494.0 & 0.0862 & 106.5 & 74.4 & 85.05 \\
\hline
\end{tabular}

\section{EIS investigation}

The EIS is a convenient and rapid approach for examining the protective properties of inhibitors onto metal surfaces in different corrosive environments (22). Thus, it was used to evaluate the effectiveness of the two aqueous extracts tested. The EIS measurements of the immersed MS in $1 \mathrm{M} \mathrm{HCl}$ medium protected with various concentrations of EO and DE at $308 \mathrm{~K}$ are depicted in Figures 5 and 6 sequentially.

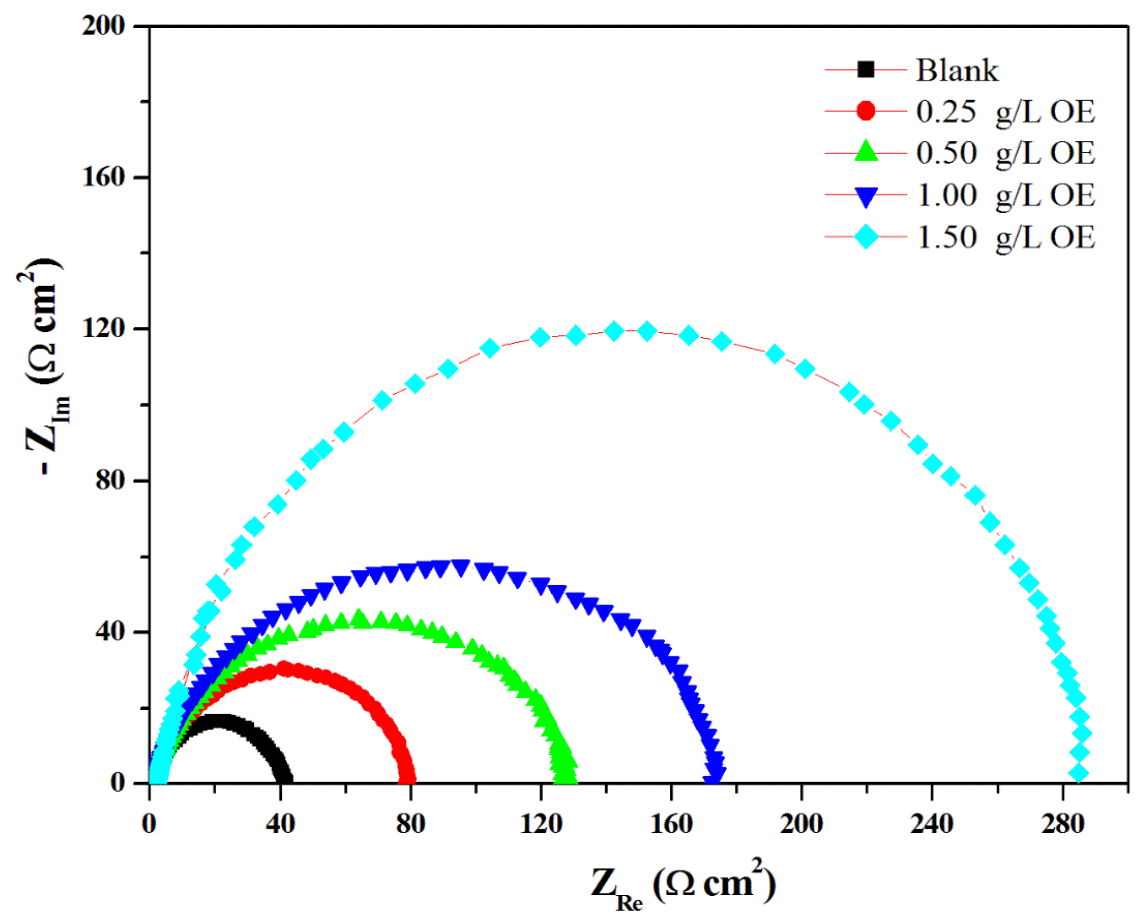

Figure 5: The Nyquist plots of the immersed $\mathrm{MS}$ in $1 \mathrm{M} \mathrm{HCl}$ without and with different concentrations of $\mathrm{OE}$ at $308 \mathrm{~K}$ 


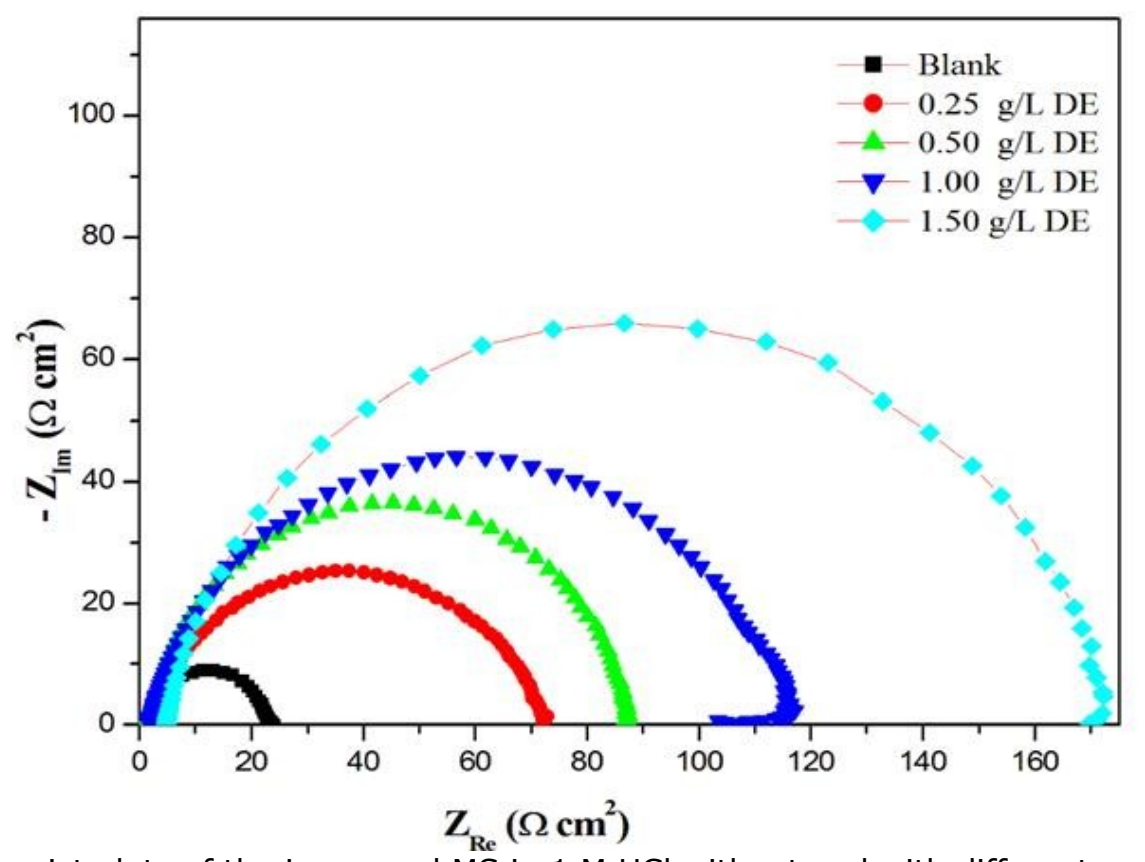

Figure 6: The Nyquist plots of the immersed $M S$ in $1 \mathrm{M} \mathrm{HCl}$ without and with different concentrations of DE at $308 \mathrm{~K}$.

In the present investigation, the Nyquist plots of EO and DE (Figures 5 and 6 ) showed a single capacitive loop whose size increases with increased concentrations of both aqueous extracts employed $(23,24)$. However, these capacitive loops are not the perfect semicircles because of a frequent dispersion effect attributing to roughness because of heterogeneous solid surface (25-27). In addition, the diameter of the Nyquist plots increases as a function of the concentration of each inhibitor, which affirms the adsorption of the EO and DE molecules on the MS surface.

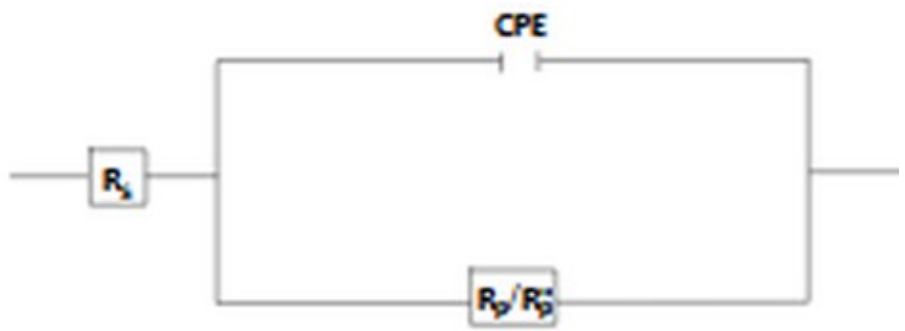

Figure 7: Equivalent circuit used to fit the experimental EIS data of the immersed $\mathrm{MS}$ in $1 \mathrm{M} \mathrm{HCl}$ without and with different concentrations of $\mathrm{OE}$ and $\mathrm{DE}$.

Furthermore, the impedance curves were fitted by using EC-LAB software, and an equivalent electrical circuits (EEC) diagram corresponds to the metal/ solution interface (the double layer between the $\mathrm{MS} / \mathrm{EO} / \mathrm{HCl}$ and $\mathrm{MS} / \mathrm{DE} / \mathrm{HCl}$ ) was proposed in Figure 7 (28-30). As reported in Figure 7, the equivalent circuit elements consisting of solution resistance $\left(R_{s}\right)$ connected in $\left(C P E_{d l}\right)$ represent the constant phase element coupled with the polarization resistance $\left(R_{p}\right)$. In this circuit, $R_{p}$ corresponds to the sum of charge transfer resistance $\left(R_{c t}\right)$ and diffuse layer resistance $\left(R_{d}\right)$ at the metal/solution interface in the absence of $O E$ and $\mathrm{DE}\left(\mathrm{R}_{\mathrm{p}}=\mathrm{R}_{\mathrm{ct}}+\mathrm{R}_{\mathrm{d}}\right)$. While that $\left(\mathrm{R}_{\mathrm{p}}{ }_{\mathrm{p}}\right)$ corresponds to the sum of $R_{p}, R_{a}$ (accumulated species) and $R_{f}$ (film resistance) in the presence of the two studied extracts $\left(R^{\prime \prime}{ }_{p}=R_{p}+R_{a}+R_{f}\right)(31,32$ ). The $C P E_{d l}$ is defined as follows:

$$
Z_{C P E}=\frac{1}{Y_{2}(j \omega)^{2}}
$$

Where $Y_{0}$ benefits from the possibility of a non-ideal capacitance of $\left(\mathrm{CPE}_{\mathrm{dl}}\right),(\omega)$ is the angular frequency and $(j)$ is the imaginary unit, and $n$ is the phase shift, which gives details about the degree of surface inhomogeneity for whole numbers $(0<n<1)$ ) $(29,33)$.

The inhibition efficiency $E_{E I S}(\%)$ is designed according to (Equation 4), where $R^{\prime \prime} p$ and $R_{p}$ are the 
polarization resistance in the presence and absence of inhibitors, respectively.

$$
I E_{E I S}(\%)=\left(R_{p i n h}^{\prime}-\frac{R_{p}}{R^{\prime}}\right) \times 100
$$

The impedance data that were fitted according to the equivalent circuit and inhibition efficiency ( $E_{E I S}$ $\%)$ are listed in Table 3. According to the fitted results, that the double layer capacitance $\left(\mathrm{C}_{\mathrm{dl}}\right)$ values were reduced for the inhibited samples, evidencing the enhancement of the $O E$ and $D E$ molecules adsorption onto the surface. The reduction of the $\left(C P E_{d l}\right)$ values for the protected samples is attributed to the replacement of water molecules adsorbed on the metal surface with the compounds of $\mathrm{OE}$ and $\mathrm{DE}$ at the metal /solution interface (34). In addition, we noticed that the values of $R_{p}$ increases with the increase of different concentrations of two aqueous extracts to reaches its maximum values 288.10 and $174.05\left(\Omega . \mathrm{cm}^{2}\right)$ at $1.5 \mathrm{~g} / \mathrm{L}$ for the $\mathrm{OE}$ and $\mathrm{DE}$ respectively. Consequently, the inhibition efficiencies (IEEIS\%) of $\mathrm{OE}$ and $\mathrm{DE}$ showed the maximum $\mathrm{IE}_{\mathrm{EIS}} \%$ is approximate $92.09 \%$ and $86.91 \%$ respectively. Thus, it reveals that the OE and DE molecules have considered as a useful green inhibitors to protect MS against corrosion and to reduce the reactive sites which could be created during corrosion phenomenon (35). These results are in good agreement with the results obtained by PDP investigation and show that $\mathrm{OE}$ has the best inhibitory performance compared to DE.

Table 3: The electrochemical data obtained from the fitting of EIS curves for MS immersed in $1 \mathrm{M} \mathrm{HCl}$ without and with various concentrations of OE and DE at $308 \mathrm{~K}$.

\begin{tabular}{|c|c|c|c|c|c|c|}
\hline $\begin{array}{c}C \\
(g / L)\end{array}$ & $\begin{array}{c}R_{s} \\
\left(\Omega \cdot \mathbf{c m}^{2}\right) \\
\end{array}$ & $\begin{array}{c}\mathbf{R p}_{\mathbf{p}} \\
\left(\Omega \cdot \mathbf{c m}^{2}\right)\end{array}$ & $\begin{array}{c}\mathrm{CPE}_{\mathrm{dl}} \\
Y_{\mathrm{o}}\left(\times 10^{6} \mathrm{~S}^{\mathrm{n}} \Omega^{-1} \mathrm{~cm}^{-2}\right)\end{array}$ & $\mathbf{n}$ & 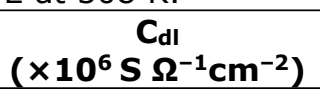 & $\begin{array}{l}\text { IE }_{\mathrm{EIS}} \\
(\%)\end{array}$ \\
\hline \multicolumn{7}{|l|}{ Blank } \\
\hline 0.00 & 1.699 & 22.78 & 327.88 & 0.902 & 92.88 & - \\
\hline \multicolumn{7}{|l|}{ EO } \\
\hline 0.25 & 1.731 & 80.08 & 223.09 & 0.891 & 58.27 & 71.55 \\
\hline 0.50 & 1.772 & 133.02 & 118.18 & 0.866 & 45.72 & 82.87 \\
\hline 1.00 & 1.821 & 174.72 & 94.08 & 0.925 & 42.02 & 86.96 \\
\hline 1.50 & 1.891 & 288.10 & 84.80 & 0.851 & 37.88 & 92.09 \\
\hline \multicolumn{7}{|l|}{ DE } \\
\hline 0.25 & 1.701 & 76.08 & 258.01 & 0.888 & 64.07 & 70.05 \\
\hline 0.50 & 1.752 & 87.98 & 175.11 & 0.849 & 54.00 & 74.10 \\
\hline 1.00 & 1.791 & 117.67 & 107.18 & 0.981 & 42.52 & 80.64 \\
\hline 1.50 & 1.823 & 174.05 & 93.22 & 0.893 & 39.75 & 86.91 \\
\hline
\end{tabular}

\section{Kinetics/Activation parameters}

Inhibitory performance as a function of temperature ( $T$ ) has been discussed in this part. It is understood that the variation of the corrosion rate as a function of temperature gives results that make it possible to thermodynamically demonstrate the mechanism of $\mathrm{OE}$ and $\mathrm{DE}$ adsorption onto an MS surface. According to the Arrhenius plot $\mathrm{Ln}(\mathrm{W} / \mathrm{T})$ versus $10^{3} / \mathrm{T}$, we calculated the enthalpy $\Delta \mathrm{H}^{\circ}{ }_{\mathrm{a}}$ and entropy $\Delta \mathrm{S}^{\circ}$ a energies; then the standard activation $\mathrm{E}^{\circ}{ }_{\text {a }}$ was calculated from the plot of $\ln (\mathrm{W})$ against $10^{3} / \mathrm{T}$. These parameters are associated for MS without and with inhibitors basing on the following equations: Equation 5 for $\Delta \mathrm{H}^{\circ}{ }_{\mathrm{a}}$ and $\Delta \mathrm{S}^{\circ}{ }_{\mathrm{a}}$ energies (36) and Equation 6 for $\mathrm{E}^{\circ}{ }_{\mathrm{a}}$ energy (37).

$$
\ln \left[\frac{W}{\mathrm{~T}}\right]=\ln \left[\left(\frac{\mathrm{R}}{\mathrm{N}_{a} \mathrm{~h}}\right)+\frac{\Delta \mathrm{S}_{a}^{\circ}}{\mathrm{R}}\right]+\left[\frac{-\Delta \mathrm{H}_{a}^{\circ}}{\mathrm{R} \mathrm{T}}\right]
$$

The outputted parameters from the Arrhenius plot (Figures 8 and 9) are listed in Table 4.

$$
\ln W=\ln A^{\prime}+\left[\frac{-E_{a}^{\circ}}{R T}\right]
$$

Where $\mathrm{W}, \mathrm{R}, \mathrm{T}, \mathrm{h}$ and $\mathrm{N}_{\mathrm{a}}$ signify the corrosion rate, the universal constant of the ideal gas, the absolute temperature, the Planck's constant and universal Avogadro number, respectively. 

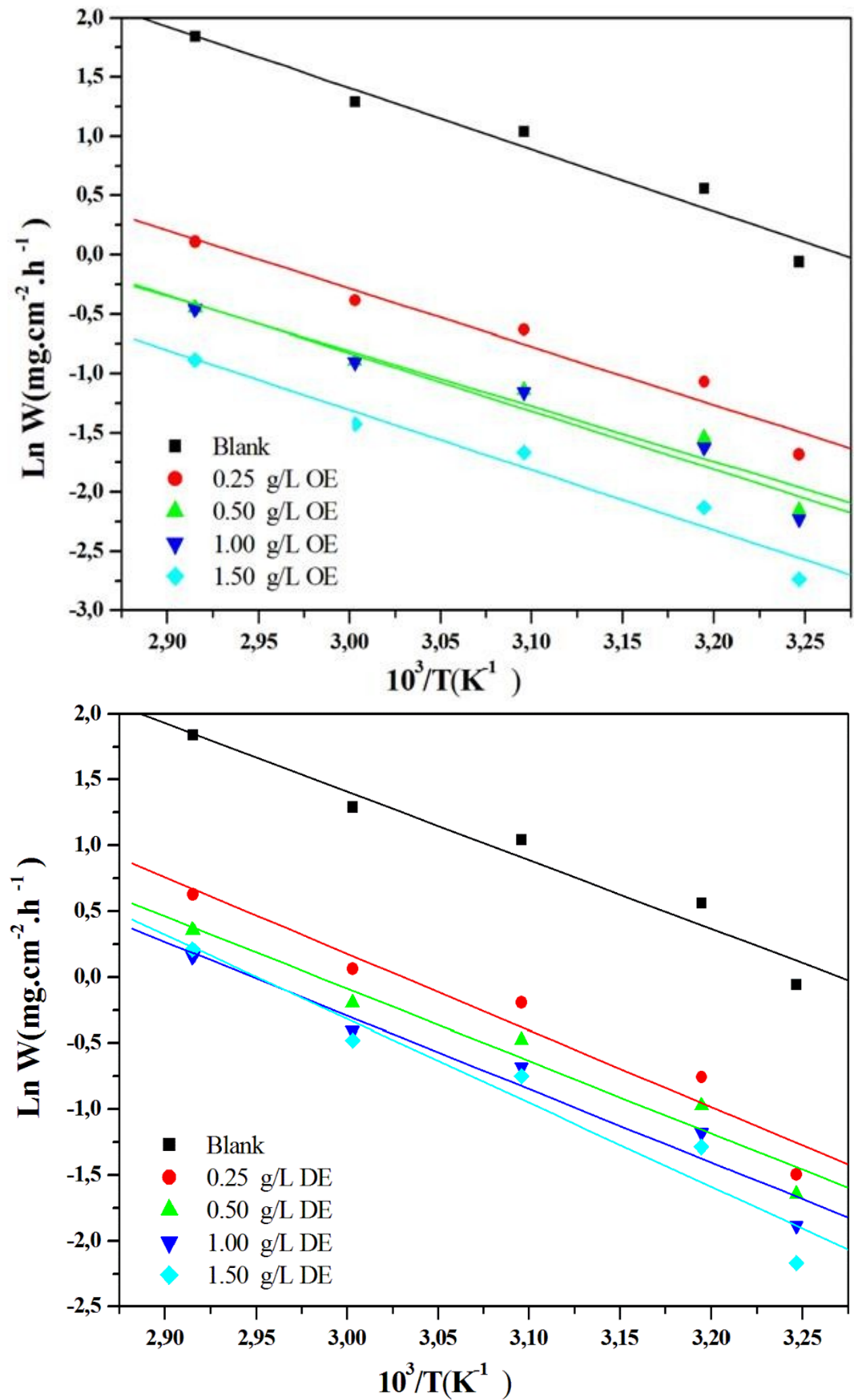

Figure 8: Arrhenius plots for $\mathrm{MS}$ corrosion rates (W) in $1 \mathrm{M} \mathrm{HCl}$ in the absence and presence of different concentrations of each inhibitor. 

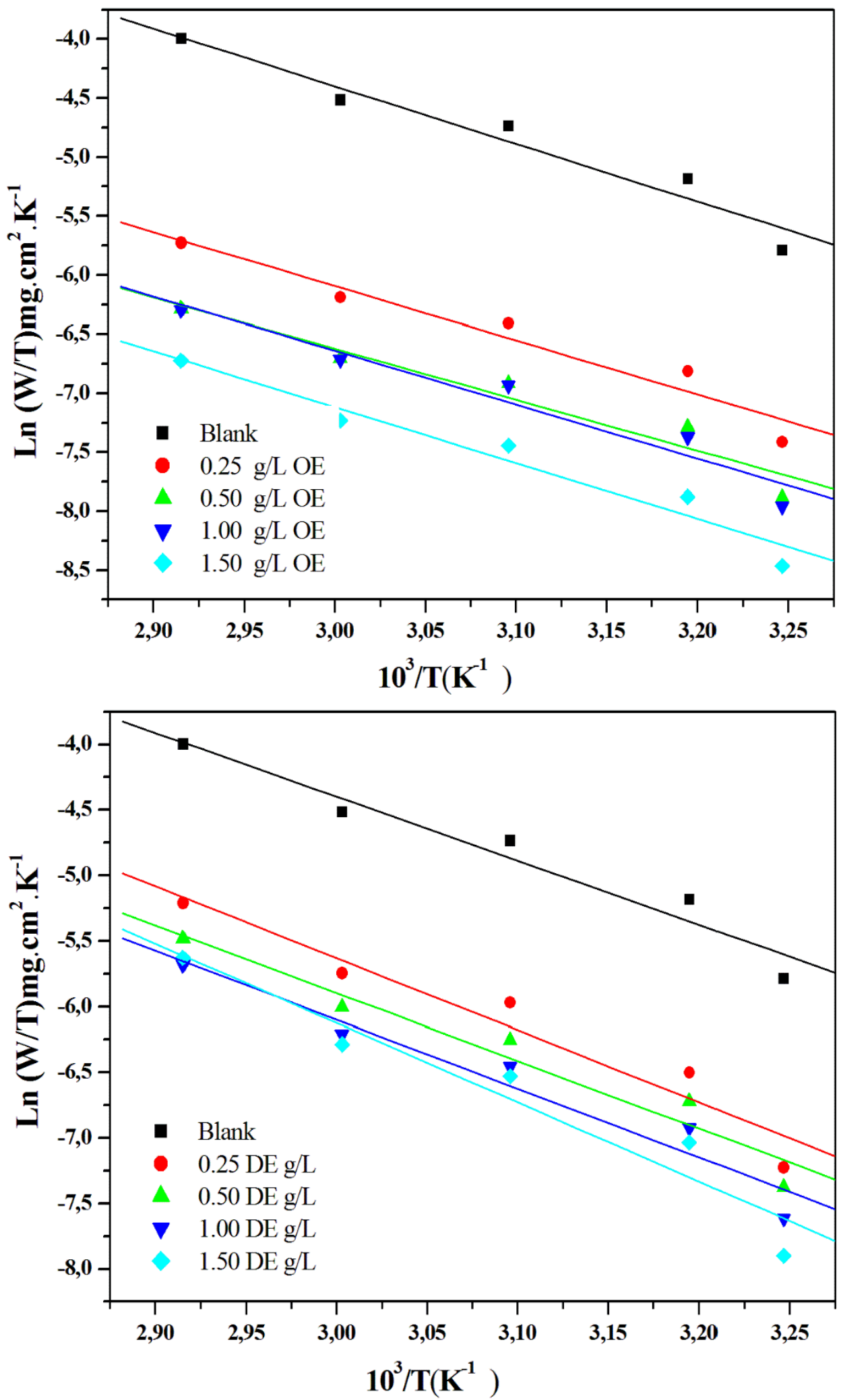

Figure 9: Transition-state plots for $\mathrm{MS}$ corrosion rates (W) in $1 \mathrm{M} \mathrm{HCl}$ in the absence and presence of various concentrations of each inhibitor. 
Table 4: Enthalpy $\Delta \mathrm{H}^{\circ}$ a and entropy $\Delta \mathrm{S}^{\circ}{ }_{\mathrm{a}}$ energies for MS without and with various concentrations of $\mathrm{OE}$ and DE.

\begin{tabular}{|c|c|c|c|c|c|}
\hline & $C(g / L)$ & $\begin{array}{c}\mathrm{E}^{\circ} \mathrm{a} \\
\left(\mathrm{kJ} \cdot \mathrm{mol}^{-1}\right)\end{array}$ & $\begin{array}{c}\Delta H^{\circ} \mathrm{a} \\
\left(\mathrm{kJ} . \mathrm{mol}^{-1}\right)\end{array}$ & $\begin{array}{c}E_{a}-\Delta H^{\circ}{ }_{a} \\
\left(k J \cdot \mathrm{mol}^{-1}\right)\end{array}$ & $\begin{array}{c}\Delta S^{\circ} \mathrm{a} \\
\left(\text { J. } \mathrm{mol}^{-1} \cdot \mathrm{K}^{-1}\right)\end{array}$ \\
\hline \multirow{5}{*}{ OE } & $1 \mathrm{M} \mathrm{HCl}$ & 43.35 & 40.65 & 2.70 & -112.32 \\
\hline & 0.25 & 40.74 & 38.04 & 2.70 & -134.24 \\
\hline & 0.50 & 38.62 & 35.92 & 2.70 & -145.00 \\
\hline & 1.00 & 40.69 & 38.00 & 2.70 & -138.91 \\
\hline & 1.50 & 42.11 & 39.42 & 2.70 & -138.61 \\
\hline \multirow{4}{*}{ DE } & 0.25 & 48.29 & 45.59 & 2.71 & -122.13 \\
\hline & 0.50 & 45.66 & 42.96 & 2.70 & -117.86 \\
\hline & 1.00 & 46.35 & 43.65 & 2.70 & -117.45 \\
\hline & 1.50 & 52.96 & 50.26 & 2.71 & -97.82 \\
\hline
\end{tabular}

It is crystal clear from the data in Table 4 that the increase of Ew (\%)with temperature and the lower value of $E^{\circ} \mathrm{a}$ are in favor of chemisorption for $\mathrm{OE}$, but are in favor of physical electrostatic nature for DE.

Additionally, the positive value of standard activation enthalpy reveals the endothermic process of corrosion phenomenon of MS (38). However, in other words, the positive value of the standard activation entropy showed a high disorder of the inhibitors molecules during adsorption. (39).

\section{Adsorption isotherm and thermodynamic parameters}

To get information more about the adsorption and the surface behavior of $\mathrm{OE}$ and $\mathrm{DE}$ molecules, different models of adsorption isotherms including Langmuir, Temkin and Frumkin were considered with the range of temperature of 308 to $348 \mathrm{~K}$ at the different concentrations of $\mathrm{OE}$ and $\mathrm{DE}$. The equations related to these isotherms are use these formulas (40):

$$
\text { Langmuir : } \frac{\mathrm{C}}{\theta}=\frac{1}{\mathrm{~K}_{\mathrm{ads}}}+\mathrm{C}
$$

$$
\begin{aligned}
& \text { Temkin : } \ln \left[\frac{\mathrm{C}}{\theta}\right]=\ln \mathrm{K}_{\mathrm{ads}}-\mathrm{g} . \theta \\
& \text { Frumkin : } \ln \left[C \cdot\left(\frac{\theta}{1-\theta}\right)\right]=\ln \mathrm{K}_{\mathrm{ads}}+\mathrm{g} . \theta \text { (Eq. 9) }
\end{aligned}
$$

where $K_{\text {ads }}$ is adsorption coefficient, $\theta$ is the surface coverage and $C_{i n h}$ is the concentrations of the $\mathrm{OE}$ and DE.

The $K_{\text {ads }}$ values can be calculated from the intercept lines on the Cinh/ $\theta$ axis. As shown in the results Figures 10 and 11 and Table 5, the linear regression factor of this isotherm model appears close to 1 for the both aqueous extracts. it is understood that the $\mathrm{OE}$ and $\mathrm{DE}$ adsorption onto the metal followed the Langmuir isotherm. Using the following equation (Eq. 10) the standard free energy of adsorption $\Delta G^{\circ}$ ads for $\mathrm{OE}$ and $\mathrm{DE}$ was calculated:

$$
\mathrm{K}_{\mathrm{ads}}=\frac{1}{55.5} \exp \left(\frac{-\Delta \mathrm{G}^{\circ} \mathrm{ads}}{\mathrm{RT}}\right) \text { (Eq. 10) }
$$

where $\mathrm{R}, \mathrm{T}, 55.5$ are gas constant, absolute temperature of experiment the molar concentration of water in solution in respectively. 


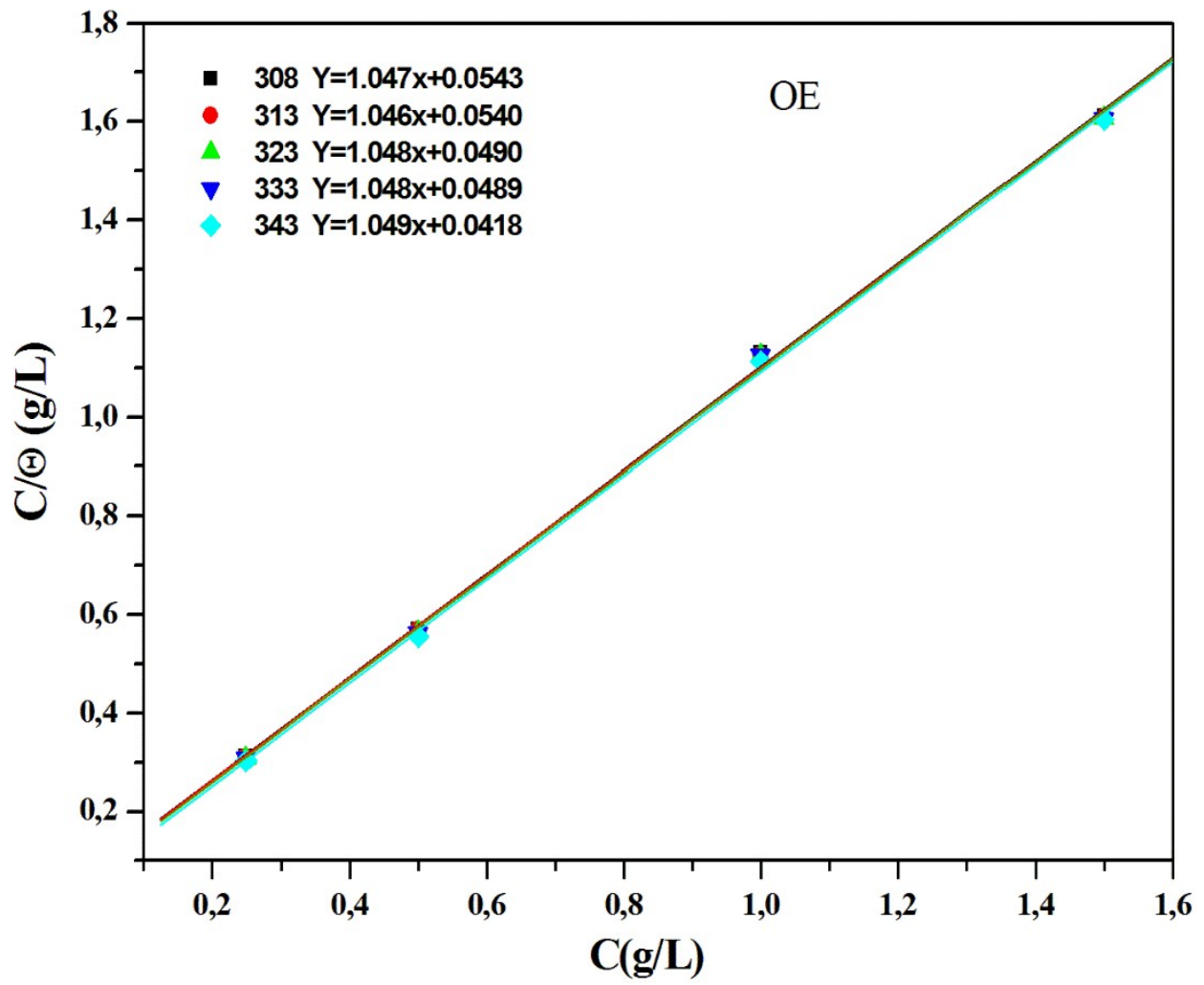

Figure 10: The Langmuir adsorption isotherm of $\mathrm{OE}$ on the $\mathrm{MS}$ surface in $1 \mathrm{M} \mathrm{HCl}$ at different temperatures.

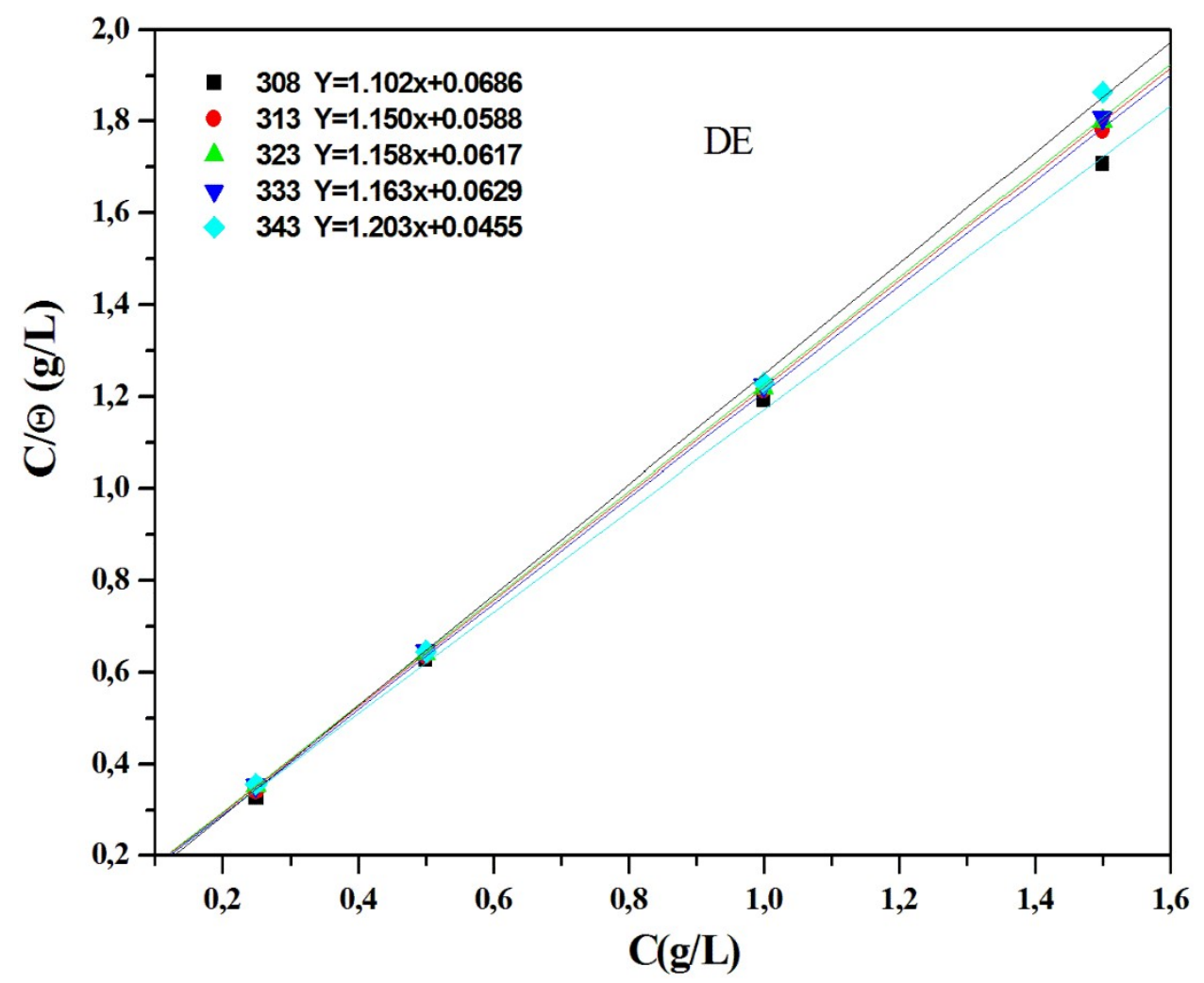

Figure 11: The Langmuir adsorption isotherm of DE on the MS surface in $1 \mathrm{M} \mathrm{HCl}$ at different temperatures. 
Table 5: Langmuir isotherm adsorption parameters for $1 \mathrm{M} \mathrm{HCl} / \mathrm{OE}$ and DE/MS interface at various

\begin{tabular}{|c|c|c|c|c|}
\hline & $\mathbf{T}(\mathbf{K})$ & $\mathbf{R}^{\mathbf{2}}$ & Kads (L. $\left.g^{-1}\right)$ & $\Delta G^{\circ}$ ads (KJ. $\mathrm{mol}^{-1}$ ) \\
\hline \multirow{5}{*}{ OE } & 308 & 0.999 & 18.41 & -25.66 \\
\hline & 313 & 0.999 & 18.51 & -25.58 \\
\hline & 323 & 0.999 & 20.40 & -26.66 \\
\hline & 333 & 0.999 & 20.49 & -27.50 \\
\hline & 343 & 0.999 & 24.39 & -28.82 \\
\hline \multirow{5}{*}{ DE } & 308 & 0.999 & 14.70 & -24.58 \\
\hline & 313 & 0.999 & 17.24 & -25.40 \\
\hline & 323 & 0.998 & 16.39 & -26.07 \\
\hline & 333 & 0.999 & 16.12 & -26.84 \\
\hline & 343 & 0.999 & 22.02 & -28.56 \\
\hline
\end{tabular}

We can conclude from Table 5, OE has a greater value indicating its ability to be absorbed easily and strongly (41). Also, it is clear that, the negative values of $\Delta \mathrm{G}^{\circ}$ ads suggest that the adsorption of inhibitor molecules onto MS surface is a spontaneous phenomenon. The predominant adsorption mode of $\mathrm{OE}$ and DE depends upon factors such as the nature of the extract molecules, type of acid anion, as well as chemical changes in the extracts. Molecular adsorption of the $\mathrm{OE}$ and $\mathrm{DE}$ at the metal surface can be attributed to the presence of electronegative elements such as oxygen and nitrogen atoms and also to the presence of $\Pi$-electrons. The high inhibitive performance of $\mathrm{OE}$ is due probably to the synergic effect of their volatile especially, E-anethole (15.4\%), (E)heptadeca-10,16-dien-7-one (11.1\%), and Z- $\beta$ ocimene $(8.6 \%)$ were identified as major constituents of the essential oil from Aaronsohnia pubescens subsp. pubescens and non-volatile compounds. These results are coherent those of the studies previously reported in our group (12).

\section{CONCLUSION}

The experimental results showed that the odorized aqueous extract (OE) and deodorized aqueous extract (DE) of Aaronsohnia pubescens subsp. pubescens proved significant corrosion inhibition activity. PDP curves demonstrate that inhibitors acts as a mixed type inhibitor in $1 \mathrm{M} \mathrm{HCl}$. The inhibition is accomplished by a mixture physical and chemical adsorption of the extract components on the MS surface. The aqueous extracts obeys a Lagmuir adsorption isotherm. The Nyquist diagram showed that adsorption mechanism of $\mathrm{OE}$ and $\mathrm{DE}$ are governed by a charge transfer process. The high protective efficiency of $\mathrm{OE}$ is due to the synergic effect of their volatile and non-volatile molecules.

\section{REFERENCES}

1. Al-Azawi KF, Mohammed IM, Al-Baghdadi SB, Salman TA, Issa HA, Al-Amiery $A A$, et al. Experimental and quantum chemical simulations on the corrosion inhibition of mild steel by $3-((5-(3,5-$ dinitrophenyl)-1,3,4-thiadiazol-2-yl)imino)indolin-2one. Results in Physics. 2018 Jun;9:278-83. <DOI .

2. Dehghani A, Bahlakeh G, Ramezanzadeh B, Ramezanzadeh $M$. Potential of Borage flower aqueous extract as an environmentally sustainable corrosion inhibitor for acid corrosion of mild steel: Electrochemical and theoretical studies. Journal of Molecular Liquids. 2019 Mar;277:895-911. <DOI>.

3. Ghames A, Douadi T, Issaadi S, Sibous L, Alaoui K. Theoretical and Experimental Studies of Adsorption Characteristics of Newly Synthesized Schiff Bases and their Evaluation as Corrosion Inhibitors for Mild Steel in $1 \mathrm{M} \mathrm{HCl}$. Int J Electrochem Sci. 2017 Jun;12:4867-97. <DOI.

4. Kumar A, Trivedi M, Bhaskaran B, Kishore Sharma R, Singh G. Synthetic, spectral and structural studies of a Schiff base and its anticorrosive activity on mild steel in $\mathrm{H} 2 \mathrm{SO} 4$. New J Chem. 2017;41(16):8459-68. <DOI>.

5. Chraka A, Raissouni I, Seddik NB, Khayar S, Mansour AI, Tazi S, et al. Identification of Potential Green Inhibitors Extracted from Thymbra capitata (L.) Cav. for the Corrosion of Brass in $3 \% \mathrm{NaCl}$ Solution: Experimental, SEM-EDX Analysis, DFT Computation and Monte Carlo Simulation Studies. J Bio Tribo Corros. 2020 Sep;6(3):80. <DOI>.

6. El Ouadi Y, Bouyanzer A, Majidi L, Paolini J, Desjobert J-M, Costa $\mathrm{J}$, et al. Evaluation of 
Pelargonium extract and oil as eco-friendly corrosion inhibitor for steel in acidic chloride solutions and pharmacological properties. Res Chem Intermed. 2015 Oct;41(10):7125-49. <DOI>.

7. Manssouri $M$, Znini $M$, El Ouadi $Y$, Laghchimi $A$, Ouakki M, Majidi L. Effect of Aaronsohnia Pubescens Extracts to Prevent Against the Corrosion of Mild Steel in $1.0 \mathrm{M} \mathrm{HCl}$. Analytical and Bioanalytical Electrochemistry. 2020;12(7):944-58.

8. Benabbouha $T$, Siniti $M$, El Attari $H$, Chefira $K$, Chibi F, Nmila R, et al. Red Algae Halopitys Incurvus Extract as a Green Corrosion Inhibitor of Carbon Steel in Hydrochloric Acid. J Bio Tribo Corros. 2018 Sep;4(3):39. <DOI>.

9. Anupama KK, Joseph A. Experimental and Theoretical Studies on Cinnamomum verum Leaf Extract and One of Its Major Components, Eugenol as Environmentally Benign Corrosion Inhibitors for Mild Steel in Acid Media. J Bio Tribo Corros. 2018 Jun;4(2):30. <DOI>.

10. Gonzalez-Rodriguez JG, Gomez-Guzman NB, Porcayo-Calderon J. Corrosion Inhibition of $X 70$ Pipeline Steel Under Hydrodynamic Conditions of CO2 with Amide Extraction from Coffee Bagasse. J Bio Tribo Corros. 2021 Sep;7(3):86. <DOI>.

11. Manssouri M, El Ouadi Y, Znini M, Costa J, Bouyanzer A, Desjobert $J$, et al. Adsorption proprieties and inhibition of mild steel corrosion in $\mathrm{HCl}$ solution by the essential oil from fruit of Moroccan Ammodaucus leucotrichus. J Mater Environ Sci. 2015;6(3):631-46.

12. Manssouri $M$, Znini $M$, Ansari A, Bouyenzer $A$, Faska Z, Majidi L. Odorized and deodorized aqueous extracts of Ammodaucus leucotrichus fruits as green inhibitor for C38 steel in hydrochloric acid solution. Der Pharma Chemica. 2014;6(6):331-45.

13. Manssouri M, Znini M, Lakbaibi Z, Ansari A, El Ouadi Y. Experimental and computational studies of perillaldehyde isolated from Ammodaucus leucotrichus essential oil as a green corrosion inhibitor for mild steel in $1.0 \mathrm{M} \mathrm{HCl}$. Chem Pap. 2021 Mar;75(3):1103-14. <DOI $>$.

14. Manssouri $M$, Laghchimi $A$, Ansari A, Znini $M$, Lakbaibi Z, El Ouadi Y, et al. Effect of Santolina pectinata (Lag.) Essential Oil to protect against the corrosion of Mild steel in $1.0 \mathrm{M} \mathrm{HCl}$ : Experimental and quantum chemical studies. MediterrJChem, 2020 Mar 17;10(3):253-68. <DOI>.

15. Manssouri $M$, Znini $M$, El Ouadi $Y$, Ansari $A$, Costa J, Majidi L. Essential Oil of Aaronsohnia Pubescens Subsp. Pubescens as Novel Eco-Friendly Inhibitor for Mild Steel in $1.0 \mathrm{M} \mathrm{HCl}$. Analytical and Bioanalytical Electrochemistry. 2020;12(6):841-56.
16. Manssouri M, Znini M, Lakbaibi Z, El Ouadi $Y$, Majidi L. Aqueous extracts of Santolina pectinata lag., aerial parts as green corrosion inhibitor for mild steel in $1.0 \mathrm{M} \mathrm{HCl}$. Analytical and Bioanalytical Electrochemistry. 2020;12(5):607-24.

17. Manssouri M, Lakbaibi Z, Znini M, Ouadi YEL, Jaafar A, Majidi L. Impact of Aaronsohnia pubescens Essential Oil to Prevent Against the Corrosion of Mild Steel in $1.0 \mathrm{M} \mathrm{HCl}$ : Experimental and Computational Modeling Studies. J Fail Anal and Preven. 2020 Dec;20(6):1939-53. <DOI>.

18. Manssouri M, Znini M, Majidi L. Studies on the antioxidant activity of essential oil and various extracts of Ammodaucus leucotrichus Coss. \& Dur. Fruits from Morocco. Journal of Taibah University for Science. 2020 Jan 1;14(1):124-30. <DOI>.

19. Dapkevicius A, Venskutonis $R$, van Beek TA, Linssen JP. Antioxidant activity of extracts obtained by different isolation procedures from some aromatic herbs grown in Lithuania. Journal of the Science of Food and Agriculture. 1998;77(1):140-6.

20. Satapathy AK, Gunasekaran G, Sahoo SC, Amit $\mathrm{K}$, Rodrigues PV. Corrosion inhibition by Justicia gendarussa plant extract in hydrochloric acid solution. Corrosion 2009 Dec;51(12):2848-56. <DOI>.

21. Ezuber $\mathrm{H}$, Alshater A, Nisar $\mathrm{S}$, Gonsalvez A, Aslam S. Effect of surface finish on the pitting corrosion behavior of sensitized AISI 304 austenitic stainless steel alloys in $3.5 \% \mathrm{NaCl}$ solutions. Surface Engineering and Applied Electrochemistry. 2018;54(1):73-80.

22. Khalili Dermani A, Kowsari E, Ramezanzadeh B, Amini R. Utilizing imidazole based ionic liquid as an environmentally friendly process for enhancement of the epoxy coating/graphene oxide composite corrosion resistance. Journal of Industrial and Engineering Chemistry. 2019 Nov;79:353-63. $<$ DOI $>$.

23. Jamil HE, Montemor MF, Boulif $R$, Shriri $A$, Ferreira MGS. An electrochemical and analytical approach to the inhibition mechanism of an aminoalcohol-based corrosion inhibitor for reinforced concrete. Electrochimica Acta. 2003 Oct;48(23):3509-18. <DOI>.

24. Sathiya Priya AR, Muralidharan VS, Subramania A. Development of Novel Acidizing Inhibitors for Carbon Steel Corrosion in 15\% Boiling Hydrochloric Acid. CORROSION. 2008 Jun;64(6):541-52. $\leq$ DOI $>$.

25. Hsissou R, Benhiba F, Abbout S, Dagdag O, Benkhaya S, Berisha $A$, et al. Trifunctional epoxy 
polymer as corrosion inhibition material for carbon steel in $1.0 \mathrm{M} \mathrm{HCl}$ : MD simulations, DFT and complexation computations. Inorganic Chemistry Communications. 2020 May;115:107858. <DOI>.

26. Yanardağ T, Bayraktar N, Yanardağ YK, Özgen $Y$, Aksut AA. THE INHIBITOR EFFECTS OF CANNABIS SATIVA L. EXTRACTS ON THE CORROSION OF ALUMINIUM in H2SO4 SOLUTIONS. Communications Faculty of Sciences University of Ankara Series B Chemistry and Chemical Engineering. 2020 Jun $30 ; 62(1): 12-22$. $\leq U R L>$.

27. Arrousse N, Salim R, Abdellaoui A, Hajjaji FE, Hammouti B, Mabrouk EH, et al. Synthesis, characterization, and evaluation of xanthene derivative as highly effective, nontoxic corrosion inhibitor for mild steel immersed in $1 \mathrm{M} \mathrm{HCl}$ solution. Journal of the Taiwan Institute of Chemical Engineers. 2021 Mar;120:344-59. <DOI>.

28. Benali O, Benmehdi H, Hasnaoui O, Selles C, Salghi R. Green corrosion inhibitor: inhibitive action of tannin extract of Chamaerops humilis plant for the corrosion of mild steel in $0.5 \mathrm{MH} 2 \mathrm{so} 4$. J Mater Environ Sci. 2013;4(1):127-38.

29. Hsu CH, Mansfeld F. Technical Note: Concerning the Conversion of the Constant Phase Element Parameter YO into a Capacitance. Corrosion. 2001 Sep 1;57(09).

30. Yildiz R. An electrochemical and theoretical evaluation of 4,6-diamino-2-pyrimidinethiol as a corrosion inhibitor for mild steel in $\mathrm{HCl}$ solutions. Corrosion Science. 2015 Jan;90:544-53. <DOI>.

31. Solmaz R, Kardaş G, Çulha M, Yazıcı B, Erbil M. Investigation of adsorption and inhibitive effect of 2mercaptothiazoline on corrosion of mild steel in hydrochloric acid media. Electrochimica Acta. 2008 Aug;53(20):5941-52. <DOI>.

32. Erbil M. The determination of corrosion rates by analysis of $A C$ impedance diagrams. Chimica Acta Turcica. 1988;1:59-70.

33. Özcan M, Dehri İ. Determination of impedance parameters for mild steel/ $\mathrm{HCl}$ interface using integration method. Corrosion Science. 2012 Jan;54:201-4. <DOI>.

34. Chai C, Xu Y, Li D, Zhao X, Xu Y, Zhang L, et al. Cysteamine modified polyaspartic acid as a new class of green corrosion inhibitor for mild steel in sulfuric acid medium: Synthesis, electrochemical, surface study and theoretical calculation. Progress in Organic Coatings. 2019 Apr;129:159-70. <DOI>.

35. Jüttner K. Electrochemical impedance spectroscopy (EIS) of corrosion processes on inhomogeneous surfaces. Electrochimica Acta. 1990 Oct;35(10):1501-8. <DOI .

36. Benali O, Cherkaoui O, Lallam A. Adsorption and corrosion inhibition of new synthesized Pyridazinium-Based Ionic Liquid on Carbon steel in 0.5 M H2SO4. J Mater Environ Sci. 2015;6:598606.

37. Badiea AM, Mohana KN. Effect of temperature and fluid velocity on corrosion mechanism of low carbon steel in presence of 2-hydrazino-4,7dimethylbenzothiazole in industrial water medium. Corrosion Science. 2009 Sep;51(9):2231-41. $\leq \mathrm{DOI}>$.

38. Khamis E, Bellucci F, Latanision R, El-Ashry E. Acid corrosion inhibition of nickel by 2(triphenosphoranylidene) succinic anhydride. Corrosion. 1991;47(9):677-86.

39. Bentiss F, Lebrini M, Vezin H, Chai F, Traisnel M, Lagrené $M$. Enhanced corrosion resistance of carbon steel in normal sulfuric acid medium by some macrocyclic polyether compounds containing a 1,3,4-thiadiazole moiety: AC impedance and computational studies. Corrosion Science. 2009 Sep;51(9):2165-73. <DOI>.

40. Bourazmi H, Tabyaoui M, Hattabi L, El Aoufir $Y$, Ebenso E, Ansari A. Camphor as an effective corrosion inhibitor for carbon steel in $1 \mathrm{M} \mathrm{HCl}$ solution: electrochemical and quantum chemical investigation. Journal of Materials and Environmental Science. 2018;9:1058-74.

41. Tang L, Mu G, Liu G. The effect of neutral red on the corrosion inhibition of cold rolled steel in $1.0 \mathrm{M}$ hydrochloric acid. Corrosion Science. 2003 Oct;45(10):2251-62. <DOI . 
